\title{
SENTIDOS DE PRIVACIDADE NO FACEBOOK: O CADEADO COMO PERSPECTIVA DE PODER DE COMANDO E ILUSÃO DE ESTAR NO CONTROLE
}

\author{
DIEGO HENRIQUE PEREIRA ${ }^{1}$
}

Faceca - Faculdade Cenecista de Varginha, Rua Professor Felipe Tiago Gomes

Vila Bueno, 37006-020, Varginha, MG - Brasil

diego@professordiegopereira.com.br

\begin{abstract}
RESUMO. A circulação de diferentes ferramentas disponibilizadas pela evolução tecnológica passou a produzir materialidades significativas $e$ processos discursivos que, face à memória metálica, se firmam constituindo diferentes sujeitos de discurso. Tendo como base teórica a Análise de Discurso Francesa, e perpassando pelas condições de produção de diferentes discursos que são produzidos pela materialidade digital, objetivou-se analisar e compreender o funcionamento discursivo do Facebook acerca dos sentidos de privacidade na rede social. A relevância da proposta esbarra-se na compreensão dos sentidos de 'público' e 'privado', não descartando a análise de como os efeitos destes sentidos que produzem deslizes culturais, ideológicos e históricos. Conclui-se que o discurso de privacidade na rede social Facebook produz sentidos sitiados nas representações circuladas à memória do 'cadeado', enquanto uma ferramenta tecnológica significante, por uma posição-sujeito irrigada de 'poder', podendo produzir no usuário a ilusão de estar no controle.
\end{abstract}

Palavras-chave: Facebook; cadeado; privacidade; ilusão de controle.

\begin{abstract}
The circulation of different tools made available by technological evolution began to produce significant materialities and discursive processes that, in the face of metal memory, established themselves as different subjects of discourse. Based on the French Discourse Analysis, and based on the conditions of production of different discourses that are produced by digital material, the objective was to analyze and understand the discursive functioning of Facebook about the meanings of privacy in the social network. The relevance of the proposal runs counter to the understanding of the 'public' and 'private' senses, not discarding the analysis of how the effects of these senses produce cultural, ideological and historical slips. It is concluded that the privacy discourse in the social network Facebook produces besieged meanings in the representations circulated to the memory of the 'padlock', as a significant technological tool, by an irrigated subject-position of 'power', being able to produce in the user the illusion of being in control.
\end{abstract}

Keywords: Facebook; padlock; privacy; illusion of control.

\footnotetext{
${ }^{1}$ Doutorando em Ciências da Linguagem (UNIVAS); professor e membro do Núcleo Docente Estruturante do curso de Administração (FACECA). Orientador de Cursos do Serviço Nacional de Aprendizagem Comercial (SENAC) e Consultor Organizacional (palestrante) em setores/segmentos de Gestão e de Administração. http://lattes.cnpq.br/6203332755709479.
} 


\section{Considerações iniciais}

Observa-se frequentemente, que o espaço digital dinamiza a relação entre vida real e realidade virtual. Faz movimentar, ainda, noções que são interagentes e indissolúveis, uma vez que, ao estar na rede, o sujeito projeta sua realidade na mesma e, de forma simultânea, ele a constitui (a rede) e a toma como espaço de vivências e (con)vivências cotidianas, transformando-a em um espaço doméstico. Portanto, percebese o espaço digital como uma espécie de porta que possibilita a ligação entre o usuário e a rede, seja qual for a materialidade utilizada para manter essa conexão.

O Facebook (a rede social), enquanto espaço digital, surgiu a partir de uma experiência de um jovem em Harvard, que na ocasião desenvolvia um site (software) que media a popularidade das pessoas, através de comparações entre perfis. Nos dias de hoje, traz uma memória afiliada à projeção da imagem que, não diferente de antigamente, busca evidenciar várias formas sujeito, retratando sua particularidade (traços da personalidade), sendo reais ou imaginários (KIRKPATRICK, 2011).

Objetiva-se, neste artigo, compreender o funcionamento discursivo de recortes na rede social virtual Facebook, bem como as derivas nos sentidos de privacidade que funcionam a partir do advento das tecnologias digitais. A relevância da análise esbarrase na demanda pela compreensão do funcionamento dos discursos nas materialidades apresentadas nos recortes (espaço digital), proporcionando ao leitor compreender além do texto, não buscando desvendar o implícito, mas, o que funciona nele - podendo produzir diferentes efeitos de sentidos.

Assim, trilhando os caminhos propostos pela Análise de Discurso Francesa, abordar-se-á os possíveis sentidos de 'Público' e 'Privado' que funcionam no Facebook, bem como os aparatos que tal rede virtual social disponibiliza para os usuários, mesmo que este controle seja ilusório, atentando-se às 'Responsabilidades Civis' que devem ser consideradas na produção dos sentidos.

\section{Do público ao privado: deslocamentos face a evolução tecnológica}

De acordo com Orlandi (2009), o discurso se define na/pela determinação da língua pela história, tomadas pela exterioridade, na qual o sujeito é produzido, ao mesmo tempo que produz discursos. Analisar um discurso implica em tomá-lo como objeto teórico; ou seja, como objeto histórico-ideológico, produzido a partir de práticas sociais de linguagem e manifestado em sua forma material - que é a forma encarnada na história para produzir sentidos, que no caso, os possíveis sentidos de público e privado.

Tais sentidos (de público e privado) vêm sofrendo deslizamentos e deslocamentos no decorrer da história da humanidade, em especial a partir de diferentes ferramentas colocadas pela evolução tecnológica, localizadas no início do século XXI - era em que a memória metálica (ORLANDI, 2015b) se firma constituindo diferentes sujeitos de discurso. 
A memória metálica é a memória da máquina; uma memória que não se produz pela historicidade, mas por um constructo técnico, que funciona e circula pela mídia e através das novas tecnologias de linguagem. É uma memória técnica, caracterizada pela quantidade e não historicidade, pela repetição, pela variedade e pelo acúmulo (ORLANDI, 2010).

Na era contemporânea, o sentido de público filia-se também ao capitalismo, à capacidade de qualquer indivíduo concretizar seus desejos, buscando a promoção individual, de maneira a ser socialmente aceito, podendo assim se projetar como sujeito de poder.

Nas colocações de Henge e Behenck (2008), faz-se necessário compreender que não existe um sentido literal, já posto que o sentido não pode ser qualquer um, visto que toda interpretação é regulada por condições de produção específicas. Nesta perspectiva, o sentido de público passa a ser concebido como prática social, em que a exterioridade lhe é constitutiva, e o sujeito como lugar de significação socialmente constituído.

Pode-se relacionar a constituição do sujeito, tal como hoje é conhecido, aos acontecimentos da Revolução Francesa - como por exemplo, o uso dos prenomes herdados de forma maciça, baseados na hierarquia imposta e influenciada pela Igreja Católica e pelas classes dominantes de tal época (CORBIN, 1990).

No lugar da utilização dos prenomes, os apelidos começavam a circular no meio artístico, boêmio e pelos grupos menos favorecidos, considerados sinônimos de comportamentos e ações arcaicas. Este acontecimento inaugura uma nova fase na identificação do sujeito, na qual põe em funcionamento a informalidade na abordagem dos nomes (característica latente nos dias atuais), trazendo, segundo Maldidier (2003), características potencializadas, colocando em funcionamento sentidos rotulados ao mesmo.

Ao passar do tempo, no início do século XIX, a auto identificação, feita através do espelho, inaugura uma nova forma de materialização da identidade, por meio da contemplação da própria imagem - o que oportuniza o indivíduo a se enxergar de uma maneira real, mas, ao mesmo tempo, criando fantasias ou imaginações. De certo modo, o espelho destaca a imagem (ou escritas) de si para aquele que observa, promovendo uma espécie de síntese identitária.

"[...] As escritas de si constituem objetos privilegiados quando se trata de compreender a constituição do sujeito na linguagem (ou nas linguagens) e a estruturação da própria vida como um relato - seja escrito, audiovisual ou multimídia" (SIBILIA, 2008, p. 35). Portanto, ao enunciar sobre si, mesmo que por meio do espelho, o sujeito passa a trabalhar o jogo do real e do imaginário, não vedando uma coisa da outra, mas, admitindo essa dinamicidade do 'ser' e do 'querer ser'.

Além do espelho, outro instrumento, enquanto objeto da politização do indivíduo, era o retrato. Naquela ocasião, ele era responsável por afirmar, entre a burguesia, a imagem da imposição do poder, do tradicionalismo inaugurado de geração em geração. Em síntese, o retrato reproduzia a 'imagem de si' para a sociedade aristocrata. No fim do Antigo Regime, o retrato torna-se íntimo, transcendendo da imagem imponente e 
grandiosa para miniaturas, pingentes, medalhões e coberturas de caixinhas de pó facial. A preocupação com a encenação, principalmente com o gestual, passou a tomar conta dos fotógrafos, em que a preocupação em demonstrar as boas maneiras ensinadas nas escolas fazia-se presente nos álbuns.

Segundo Payer (2005, p. 16), "são especificas as formas de interpelação da imagem na produção de sentidos. Estamos dizendo que se todo discurso tem a propriedade de produzir evidências de real; esta capacidade é diversamente potencializada no discurso produzido na base da imagem". Assim, as fotografias (imagens) cuidavam de registrar (de imprimir) o cenário (produção de sentidos) de boas maneiras (evidência real) ensinadas nas escolas.

A construção da imagem do sujeito através da fotografia funciona, na atualidade, de maneira parecida em relação ao passado, como por exemplo as redes sociais. Nestas, mesmo em condições diferentes, a projeção do indivíduo (interpelado pela ideologia) é constituído sujeito, que ocupa uma ou mais posições, a partir das diferentes maneiras em que são expostas ao público e, desta forma, construindo diferentes efeitos de sentido em relação ao que foi produzido. Ainda, segundo Payer (2005), dentro da Análise de Discurso, as imagens podem ser substituídas por palavras. Entretanto, quando juntas palavras e representações plásticas, gráficas ou fotográficas de alguém ou de algo -, temos aí, uma potencialização de consolidação de sentidos no meio social.

Além da constante busca do autoconhecimento, os indivíduos (sedentos por desvendar mistérios da vida) passam a enxergar grande importância no decifrar-se a partir de momentos de recuo ao mundo interior - uma prática comum, em meio a este tempo de conservadorismo e moderação expressiva. O exercício da introspecção é proposto pela Igreja Católica, com a intenção de levar os fiéis a compreenderem uma nova modalidade de disciplina mental e, desta forma, possibilitando uma nova forma de exploração de si: o exame de consciência. Segundo Corbin (1990, p. 458), "não menos essencial é a laicização dos procedimentos de interpretação do indivíduo, elaborados à sobra dos confessionários. A compatibilização da existência, a aritmética das horas e dos dias, que sobrecarregam o homem do século XIX”.

De acordo com Corbin (1990), alguns autores da época, baseados em Locke e Franklin, recomendavam que o dia fosse dividido em três partes de oito horas: sendo uma parte para o sono, a segunda para o trabalho e outra parte dividida entre a alimentação, exercícios físicos e o lazer. Desta forma, o registro destas atividades em diários, com a intenção de contabilizar as tarefas, evidenciou a necessidade de documentação do cotidiano, desenvolvendo, mais adiante, escritos sobre a vida amorosa. Manter o diário atualizado, além de um processo, era considerada uma forma de disciplina interior, colocando no papel aquilo que o íntimo diz.

Por tratar-se de uma prática intimista, o fechamento destes diários era feito de maneira rigorosa, utilizando trancas ou cadeados, para que os segredos de si fossem assegurados a uma intimidade individual. No interior destes escritos, revelações sobre a intimidade eram contempladas de uma forma nostálgica, analítica e, até mesmo, como fonte de arrependimentos; ao mesmo tempo, despertava a imaginação à prospecção do eu ideal, do imaginário (CORBIN, 1990). 
Vivencia-se hoje uma época aparentemente limítrofe; vivencia-se um forte marco histórico, uma passagem, na qual o poder transita tanto no contexto sócio-políticoeconômico, quanto no contexto sociocultural. Chega-se ao que chamamos de 'publicização do privado'; ou seja, chega-se à privatização dos espaços públicos, e neste impera-se o fascínio pela visibilidade e a acirrada busca da sensação de tornar-se celebridade, tomando lugar da subjetividade interior. É, neste espaço, que cenários são montados e propostos para apresentação de espetáculos estridentes: o 'show do eu' (SIBILIA, 2008). Percebe-se então, que uma sociedade massificada não é necessariamente o volume de pessoas, mas, sim, as referências que a regem - ou seja, os grupos de referência que influenciam o comportamento dos demais.

A noção de público, que foi construída ao longo dos tempos, traz, justamente, a noção de politização de ideias, segundo a qual a abrangência máxima de ouvintes e expectadores torna-se fundamental para que algo se torne público (SENNETT, 1993). Logo, os sentidos que funcionam em relação aos limites do público concernem à preservação dos espaços intimistas, em que os sentimentos refletem a interioridade, produzindo um efeito de sentido íntimo e privado.

Segundo Arendt (2007), o termo privado tem sua etimologia pautada na privação, fato de abster-se de coisas ou situações. O sujeito quando se priva de algo, deixa de vivenciar relações entre processos externos, fechando-se em si mesmo ou, até mesmo, deixando de realizar tarefas de sua própria vida.

A modernidade nos apresenta uma nova percepção do privado, em que a intenção de fechar-se na interioridade do ser ultrapassa as barreiras da vida pública, assim propiciando o fenômeno da massa da solidão, no qual desvencilha a principal intenção que a tecnologia busca colocar: o rompimento das distâncias comunicacionais - o encurtamento dos processos que dependiam do desprendimento geográfico (ARENDT, 2007).

O sacrifício de tornar-se um sujeito privado para a exaltação pública merece destaque nos anos cinquenta, em que o lar possuía uma conotação de intimidade e, logo, passa a dar lugar aos fenômenos de politização, em que a massa predomina em relação ao individual - desta forma, mais uma vez, privando as vontades próprias. De acordo com Sennett (1993), em uma sociedade moderna, em que os valores coletivos dizem prevalecerem em relação aos valores individuais, ocorre uma inversão de papéis, ou até mesmo, equívocos recorrentes na diferenciação da esfera pública e esfera privada, haja vista que, segundo Pêcheux (2006), equívocos permitem problematizar a noção de interpretação como uma (trans)formação de sentidos.

Segundo Orlandi (2009), a dimensão do virtual, tão explorada em nosso cotidiano e em nosso imaginário, nos levam a compreender que a materialidade da linguagem (seus múltiplos significantes), em sua plasticidade, incorpora os modos de existência do concreto nas suas diversas modalidades: formal (abstrato), empírico, virtual. E, todas elas nos confrontam com o significante: com seus limites, com suas falhas, seus equívocos, sua incompletude incontornável.

No início do século XXI, a memória e o esquecimento passam a ser pautas constantemente debatidas, nas artes, nos discursos científicos. São consideradas como 
preocupantes as anomalias, além dos apagões do ato de lembrar. O interesse desloca-se para a busca, incessante, da descoberta de técnicas capazes de administrar a memória, visando à otimização de seus recursos. Segundo Dias (2012), os efeitos da tecnologia sobre o discurso fazem com que a memória seja evidenciada e não apagada.

Com grande participação de usuários, e pela possível interação entre os mesmos, o advento das redes sociais virtuais têm se intensificado pela facilidade ao acesso à internet, principalmente na última década. Logo, pensar em internet é mobilizar a ideia de globalização; é conscientizar-se de que as barreiras geográficas são encurtadas pelo acesso virtual em diferentes localidades do mundo. Para Chiaretti (2016), as inovações tecnológicas têm como uma de suas consequências a promoção de novas formas de relacionamento entre os homens e novos protocolos de convivência.

A dificuldade em conciliar o 'eu público' e o 'eu privado' que levou muitas estrelas do século $\mathrm{XX}$ a sérias angústias e até suicídios, parece que está se extinguindo hoje em dia (SIBILIA, 2008). A busca de visibilidade, de satisfação do ego, de fazer do próprio 'eu' o espetáculo, pode ser uma tentativa desesperadora de preencher um velho desejo humano: o de afugentar os temerosos fantasmas da solidão. Deste modo, quando agrupados e quando inseridos em uma rede, as dificuldades e limitações do 'eu' são esquecidas, mesmo que momentaneamente, cedendo espaço para o 'show do eu' que, mesmo que irreal ou idealizado por um momento, passa a ser o que, de fato, não é - como percebido em muitos perfis no Facebook, nos dias de hoje.

\section{O cadeado: um possível 'discurso de controle' sobre a privacidade no facebook}

A sede humana pela busca da complementariedade nas diferenças imputa na humanidade a curiosidade e a motivação de conhecer o outro; contudo, ao mesmo passo, promove-lhe receio pelo fato de colocar-se à prova de julgamentos. É, justamente neste receio que reside a busca pela preservação de sua intimidade e que se oriunda o questionamento para a análise a saber: 'Como se dá o funcionamento dos efeitos de sentido produzidos pela imagem do cadeado nos ícones do Facebook’?

O Facebook, rede de maior expressão no Brasil, é caracterizado por ser um provedor de aplicações ou provedor de conteúdo que disponibiliza informações, embora nem seja autor das informações que nele vinculam-se. "Um provedor de serviços de internet é a pessoa natural ou jurídica que fornece serviços relacionados ao funcionamento da internet" (LEONARDI, 2005, p. 19). Virtualmente, disponibiliza meios para publicações diversas de seus usuários - textos, imagens e vídeos. Deste modo, sua relação estabelecida com tais usuários caracteriza-se como relação jurídica de consumo.

Em sua evolução, a tecnologia sempre se ateve ao Direito e, recentemente, ainda mais. A internet se desenvolveu numa grande velocidade e, sem dúvidas, é uma das maiores invenções da humanidade, trazendo situações e implicações que, até pouco tempo atrás, eram impensadas ou inimagináveis. Contudo, e ao mesmo tempo, demandou atenção de legisladores para a edição de uma legislação regulatória, dadas as circunstâncias de existência de relações humanas nesse âmbito. Recentemente, em 13 de 
abril de 2014, a Lei n. 12.965/14, denominada de Marco Civil da Internet (BRASIL, 2014), veio subsidiar grandes decisões.

Quer seja comissiva ou omissivamente, qualquer dano causado pelo Facebook ao seu usuário, obriga-o a indenizar o mesmo, não importando a aferição de culpa. Do mesmo jeito, por meio de qualquer que seja a conduta de um usuário - comissiva ou omissiva -, quando este mesmo causa dano a outrem, deve-se haver indenização. Segundo Diniz (2015, p. 50) "a responsabilidade civil tem como finalidade aplicar medida que obrigue alguém reparar um dano patrimonial ou moral causado a outrem".

Juridicamente, a responsabilidade civil do Facebook, pode ser explicada quando entrelaçada a três requisitos:

[...] O primeiro é a existência de uma conduta, seja ela comissiva ou omissiva, que configure um ilícito, ou seja, uma conduta contrária ao ordenamento jurídico; o segundo requisito é o dano, seja ele patrimonial ou moral, causado à vítima, em razão da conduta anteriormente citada; por fim, como terceiro requisito aparece o nexo de causalidade entre a ação e o dano, isto é, a existência de um vínculo entre a conduta e o dano causado. Por outras palavras, a existência do dano a um indivíduo deve decorrer da conduta de outro, pois uma vez inexistente essa relação de causa e efeito, não poderá se falar em responsabilidade civil. (DINIZ, 2015, p. 52)

Muito além de uma relação social, em que proporcionar interações entre pessoas seja seu principal expoente, o Facebook se assegura em aspectos jurídicos civis, precavendo-se escoltado pela lei na relação entre usuário e pessoa jurídica; explicitando, mesmo que de forma não transparente, uma relação que vai além de responsabilidade social, chegando no âmbito da responsabilidade civil.

Dentro de seu funcionamento, no momento que a empresa Facebook organiza seu layout, ela escolhe ícones (como a figura do cadeado, na página inicial do perfil), principalmente, dispondo-os na parte superior direita, conforme o recorte mostrado pela Figura 1. Por meio da função que exerce, o cadeado passa a ser associado a uma série de sentidos - que como veremos estão relacionados à privacidade.

No momento que se escolhe o lugar onde o primeiro ícone se fixará - cadeado com traços horizontais - percebe-se que o mesmo se encontra organizado como segundo ícone, da direita para a esquerda, na barra de tarefas. Dentre todos os símbolos que ali estão colocados, associando-se com determinadas formações discursivas, o cadeado se constitui com uma posição-sujeito de poder.

Observa-se uma grande adesão às redes socais, de forma evidente ao Facebook onde, na atualidade, a tecnologia nos convoca a '(re)pensar' os sentidos de público e privado. Afinal, o que funciona como sentido de privado sempre foi o mesmo? Ou, qual a esfera do sentido público e seu funcionamento na sociedade? 


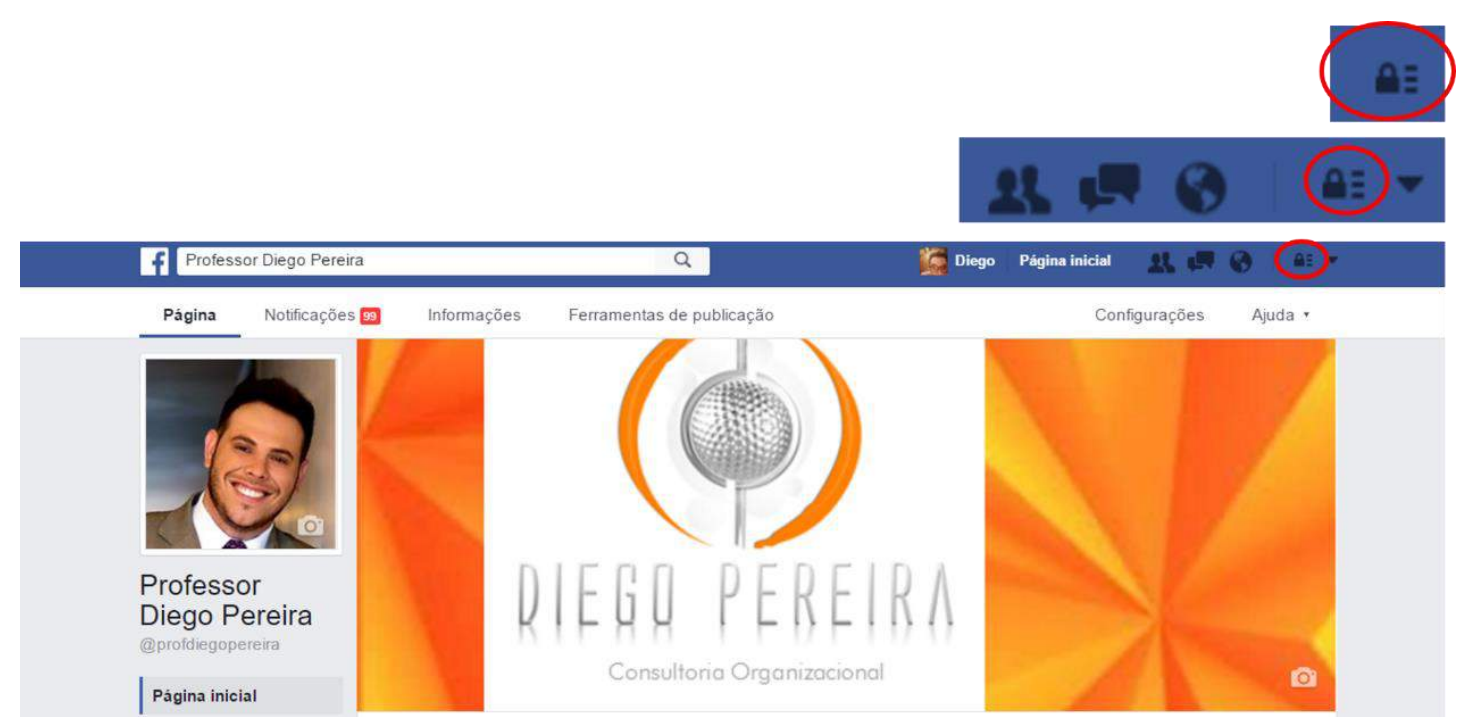

Figura 1. Página inicial do Facebook - Ícone do cadeado. Fonte: Página pessoal do Facebook (2015).

Segundo Lemos e Di Felice (2014), pensar em redes sociais, principalmente pela relação do homem com a banda larga, postula-se tanto um sujeito em funcionamento com as imagens, quanto representados pelas fotografias, potencializadas pelo desenvolvimento dos celulares, que traz maior possibilidade de interação, pela mobilidade. Em relação à postagem, o Facebook, de forma particular, traz uma dinâmica latente entre aquele que posta e aquele que visualiza a postagem - desta forma, proporcionando oportunidade destes interlocutores se movimentarem em relação às suas opiniões, independentes se estão corretas ou não.

Os ícones são formas materiais de produzir sentidos (LEMOS; DI FELICE, 2014). Em nosso caso, o ícone analisado se relaciona com o controle do usuário desta rede social em relação a quem poderá visualizar tais postagens. O sentido que o mesmo (ícone), tomado aqui como discurso, produz por meio da imagem de um cadeado, se constitui através de memórias discursivas; ou seja, os já ditos relacionados a tal imagem (cadeado). Estas memórias funcionam a partir de condições sócio históricas que relacionadas à língua, produzem a memória do dizível, que pode funcionar de duas maneiras: (1) relacionadas às memórias institucionalizadas - o arquivo posto em jogo no discurso e; (2) à memória constitutiva - o dizível, o que se pode interpretar no processo discursivo; este último pode ser chamado de interdiscurso.

Ferreira (2015) faz menções em seu texto, sobre a memória discursiva (ou interdiscurso), se embasando em Pêcheux (1988). Assim, considera que a memória discursiva seja definida em relação às formações discursivas e às formações ideológicas, sendo que determinada formação discursiva determina o caminho daquilo que foi dito, a partir de uma formação ideológica que a constitui. $\mathrm{O}$ interdiscurso recobre e recorta as diferentes formações discursivas, que está, por sua vez, em constante movimento.

O interdiscurso funciona como conjunto de formulações de dizeres já concebidos, que se filiam a outros discursos, para que façam sentido; 'no interdiscurso, fala uma voz sem nome' (COURTINE, 1984 apud ORLANDI, 2015a). Portanto, este processo derivase de inúmeros ditos que funcionam de forma simultânea; por exemplo, no caso de nosso recorte, a figura do cadeado nos traz memórias que funcionam relacionadas ao 
impedimento de algo, barreira de acesso, trancamento de informações íntimas, fechamento de acesso, isolamento do sujeito em si mesmo, prisão ou privação em relação ao mundo e impressão de segurança.

Na página do Facebook, no recorte da Figura 2, clicando neste ícone (cadeado se mostra evidente), outra aba é aberta, mostrando o enunciado: 'Atalhos de privacidade' que se relaciona à utilização deste ícone com sentidos de privacidade, que foram constituídas a partir da imagem do cadeado. Esta imagem se dá a partir de formações discursivas que põem em funcionamento a questão do 'controle da privacidade', que circula na sociedade com sentido de 'preservação da intimidade', funcionando a partir de um processo histórico que determina o que pode e deve ser dito sobre si e sobre os outros. Tais efeitos de sentidos derivam-se de questões morais, na presença de um ícone, que dispara um comando transparente a si mesmo.

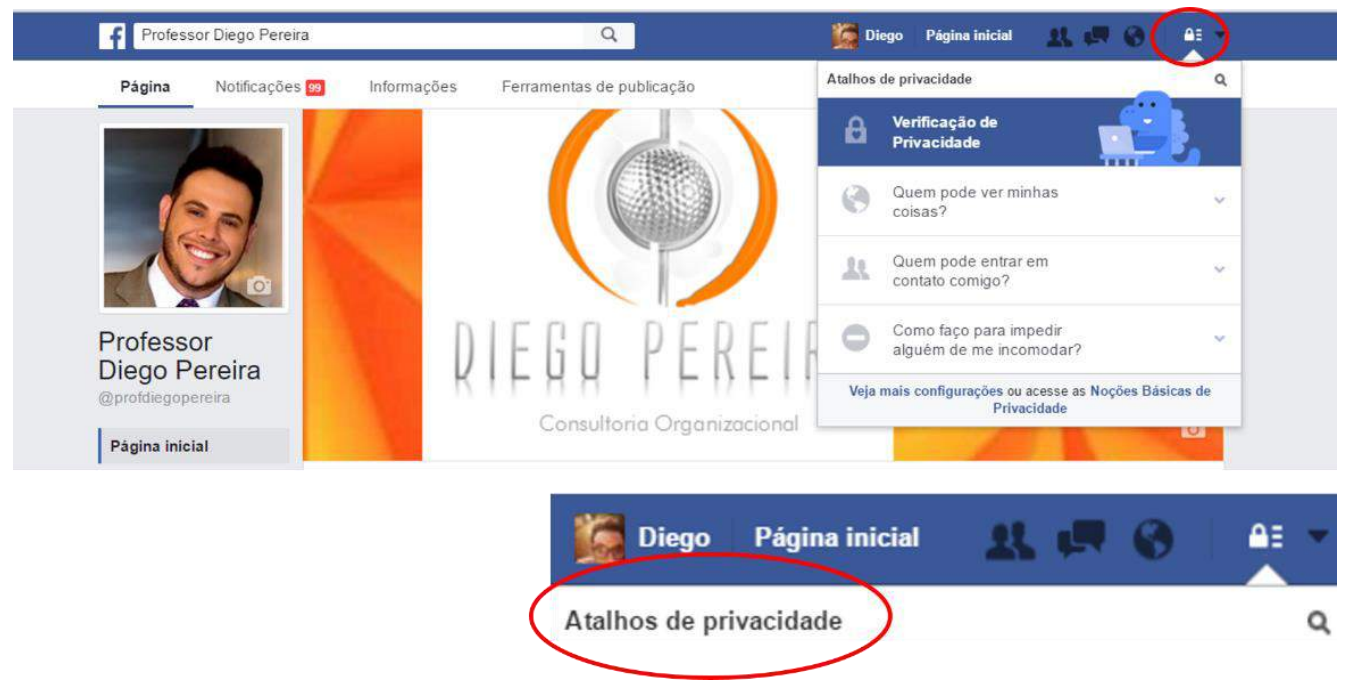

Figura 2. Barra de tarefas do Facebook - Atalhos de privacidade. Fonte: Página pessoal do Facebook (2015).

Por se configurar como um comando, pode-se pensar que ele (o cadeado) regula as práticas de privacidade por meio do controle que é exercido pelo usuário, que por sua vez, pode escolher o tipo de privacidade que gostaria de configurar em seu perfil. $\mathrm{O}$ comando engendra a possibilidade de que as ações são controladas pelo usuário que escolhe livremente, apagando todo o processo histórico sobre o que seria a privacidade 'a preservação da intimidade'. Esses sentidos passam a funcionar de maneira transparente e evidente, por meio de um ícone no Facebook que basta clicar.

[...] Essa relação injuntiva de clicar [...] produz efeitos de controle sobre o trajeto de leitura. A textualidade [...] produz, então, um efeito de leitura que demandaria uma prática específica pondo em relação ao leitor e o material, prática que seria produzida pelo gesto de clicar [...]. Contudo, as informações disponibilizadas nas páginas acessadas já estão previamente organizadas e, nessas condições, ao leitor é permitido ler o que está formulado e que ficará acessí(á)vel pela iminência do clicar. (NUNES, 2013, p. 115) 
Segundo Nunes (2013, p. 107), é pelos cliques que se estabelecem os trajetos de leitura e de interpretação, "porque ler é interpretar, e o sujeito não tem como não significar". O jogo discursivo dos sentidos nas redes sociais compõe a textualidade.

Fazendo a associação dos dizeres materializados no enunciado 'Atalho de privacidade', percebe-se que o funcionamento de formações discursivas já se estabelece através da memória do cadeado, que ali está retratado através de sua própria imagem, em relação aos traços horizontais, que representam os conteúdos que estão inscritos no interior do mesmo. Deste modo, passa a propiciar a circulação de sentidos relacionados à preservação da intimidade do usuário, mesmo se inserindo no contexto público (esta é a função das redes sociais, como a massificação e a exposição), engendrando a ilusão (pelo fato de que, na verdade, não ser totalmente controlados) da possibilidade de escolha acerca dos modos que suas postagens poderão aparecer na rede.

Quando a palavra atalho é utilizada, mobiliza-se o sentido de caminho, rapidez no trajeto, agilidade no percurso, produzindo um efeito de sentido de facilidade no acesso à rede social, uma vez que a mesma dispõe de dispositivos de fácil acesso. Contudo, segundo Chiaretti (2016), não devemos nos ater a uma compreensão dos avanços científicos a partir daquilo que 'facilitam' ou 'dificultam', mas sim a partir do modo como engendram maneiras de ser e de se relacionar-e, também de escolher.

Geralmente, os processos para a composição do dispositivo que 'comanda' as ações em uma rede social virtual (neste caso retratado pelo Facebook) são apagados, fazendo circular a noção do imediatismo da escolha (como se as escolhas fossem inconsequentes), onde através de um clique as vontades serão realizadas.

Atentando mais ainda, e se pensamos bem, nunca existiu uma tecnologia das coisas, e sim, sempre houve o homem em qualquer avanço tecnológico. A informação tecnológica, em seus avanços, se coloca no lugar de outros efeitos de linguagem, que se deslocam, quando trazemos para a frente da cena a noção de enunciado. Na visão de Orlandi (2009), saber como se elabora um texto (enunciado) para que ele circule como circula no discurso eletrônico, saber como se dá a escrita, é saber elaborar teoricamente as novas formulações que hoje se produzem.

"O homem não pode evitar a interpretação, ou ser indiferente a ela. Mesmo que ele nem perceba, ele está interpretando [...]; esse é um trabalho continuo" (ORLANDI, 2007, p. 10). A partir deste gesto de interpretação, pode-se dizer que o enunciado 'Atalhos de privacidade', ao mesmo tempo em que promove o sentido de uma facilidade, apaga o sentido de que essa escolha é enredada por questões morais e éticas, fazendo parecer que basta um clique para fazer referência ao ícone (recortado anteriormente), destacando o sentido de facilidade no manuseio do conceituado site e, ainda mais, colocando o encurtamento do caminho entre o querer e o efetivar a ação privativa - desta forma praticando a escolha de privacidade de tal postagem. Assim, "o tratamento eletrônico da informação apresentada em linguagem natural passou a funcionar como uma mecanização das formas privilegiadas [a escolha de privacidade] da comunicação humanas" (FERREIRA, 2015, p. 83).

Por conta desta hiperconexão - pelo grande volume de usuários conectados por um longo espaço de tempo (LEMOS, DI FELICE, 2014) - o sujeito busca, ao mesmo 
tempo, politizar-se e manter sua privacidade. O sujeito busca um processo dicotômico que ao mesmo tempo põe em formulação a disseminação de si e a preservação dos conteúdos intimistas, representados pelos traços sobrepostos pelo cadeado. Desta forma, percebe-se que o ícone (cadeado) e os enunciados mobilizam o sentimento de 'controle' de quem poderá visualizar tais postagens, associando-o aos deslizes nos sentidos postulados no possível 'Discurso de Controle'.

\section{A privacidade como sentidos ilusórios de poder e de comando no facebook}

A partir da relação entre os gerenciadores do Facebook e seus respectivos usuários, uma nova posição-sujeito funciona da rede: o sujeito de 'proteção', firmando uma possível parceria entre Facebook e usuário, que se dá a partir da barganha das informações coletadas pela rede e a possibilidade da inscrição e circulação na mesma. Produzindo um sentido de parceria, de acordo com o recorte da Figura 3, esta rede social virtual elabora o enunciado 'sua privacidade é muito importante para nós', explicitando a relação entre a privacidade do usuário - 'sua' - e a relação de parceria - 'nós'.

\section{facebook canatesese}

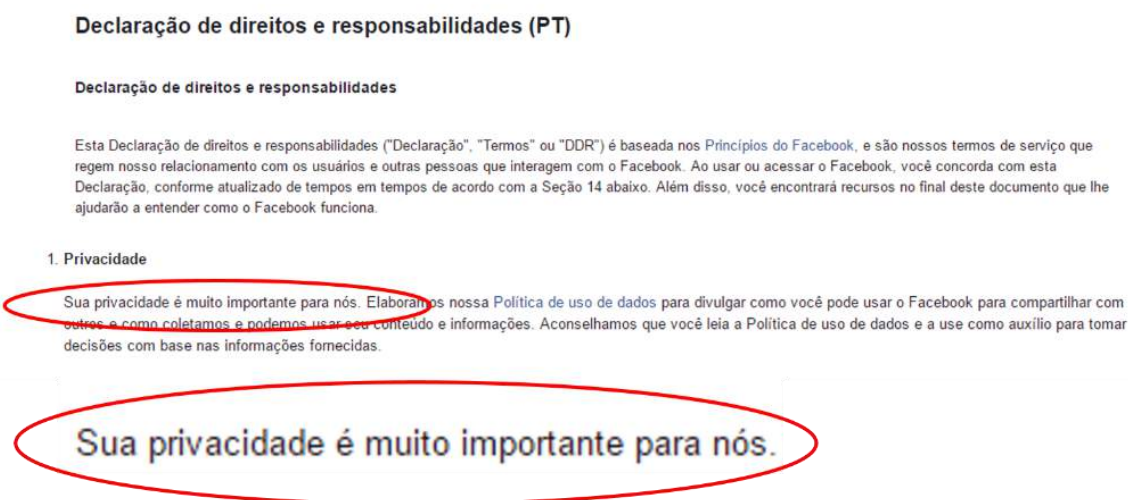

Figura 3. Termos de uso do Facebook. Fonte: Página pessoal do Facebook (2015)

No enunciado, dizer que a privacidade do usuário é 'muito importante para o Facebook', firmaria uma relação de cumplicidade, onde reconhecer a privacidade do usuário seria tarefa fundamental para o site de relacionamento. Parafraseando o enunciado, chaga-se aos dizeres: 'sua privacidade é muito importante para nós'; 'temos interesse em sua privacidade'; 'preocupamo-nos com sua privacidade'.

No método proposto pela Análise de Discurso, coloca-se em evidência a dinamicidade, o mesmo e o diferente dos processos parafrásticos e polissêmicos, simultaneidade que circula em diferentes efeitos de sentido parafraseados. Segundo Orlandi (2015a), um processo parafrástico está relacionado à memória do arquivo - ou seja, a memória institucionalizada, que conduz à estabilização. Refere-se a todo dizer, 
mantido e dizível. Já a polissemia está atrelada à memória constitutiva, pelo esquecimento permissivo ao deslocamento, à ruptura do processo de significação.

A paráfrase relaciona-se à repetição, relaciona-se à variedade do mesmo e à produtividade. Ela se faz matriz dos sentidos, haja vista que não há sentidos sem repetições, sem sustentações do saber discursivo. Tais constantes de percepções históricas e de percepções sociais podem se concretizar numa espécie de conhecimento social, capaz de orientar comportamentos dos sujeitos na promoção da direção do que é - ou não é aceitável pelos grupos sociais que se inserem (ORLANDI, 2015a).

A polissemia, atrela-se a ruptura, ao deslocamento de regras, de criações e criatividades, e interrompe o diferente, ao mesmo passo em que simula movimentos distintos de sentidos em um mesmo objeto simbólico - objeto este, fonte da linguagem, da condição de existência de discursos, até mesmo porque, "se os sentidos (e os sujeitos) não fossem múltiplos, não pudessem ser outros, não haveria necessidade de dizer" (ORLANDI, 2015a, p. 38).

Retomando a análise, a partir do momento que a empresa diz 'sua privacidade é muito importante para nós', uma relação de 'fidelidade' com o usuário é colocada em funcionamento, principalmente quando a mesma diz que a privacidade é muito importante, enunciado em que o 'muito' representa o 'além do esperado'.

De uma forma mais explícita e direta, esta rede virtual poderia utilizar o dizer 'temos interesse em sua privacidade', deixando claro ao usuário que, a partir do momento que aceita os termos de uso, uma troca de interesses é posta em funcionamento, formulando um sujeito livre, autônomo e no controle de sua privacidade.

Na mesma formação discursiva do primeiro enunciado, a paráfrase 'preocupamonos com sua privacidade', instaura um sujeito que, novamente, leva em consideração a privacidade do usuário, mostrando-se compadecido com o mesmo; ou seja, produzindo um novo efeito de sentido.

Ao mesmo tempo que a referida rede coloca à disposição do usuário ferramentas de atalho, o sentido de 'facilidade' é colocado em funcionamento, apagando o sentido de que as escolhas fazem parte de um processo, no qual diversas questões se põem em jogo: processos éticos e morais, engendrando a 'cultura do controle', fazendo parecer que basta um clique para que nossas vontades sejam efetivadas (BAUMAN, 2000).

Adentrando à 'política de privacidade' do Facebook, um novo recorte se coloca como objeto de análise - mostrado pela Figura 4 -, compondo os 'termos de uso' do software, a partir do texto 'Você está no comando'. Do ponto de vista da Análise de Discurso, neste espaço discursivo em 'sujeito controlador ideal' se inscreve na história através de memórias relacionadas ao comando; ou melhor, à ambição e à constante busca do sujeito por comandar situações.

No espaço midiático, principalmente o que concerne a materialidade digital, uma nova realidade é colocada em desenvolvimento: a da ilusão de 'ser livre' (BAUMAN, 2000). O sujeito, ao aceitar as condições estabelecidas na política de uso de tal rede social (na maioria das vezes, não lendo, muito menos interpretando estes textos), se sujeita a 
interagir (mesmo que não explicitamente, às realidades impostas por tal software), tendo a ilusão de estar no controle de suas ações, no mesmo. Percebe-se que não existe controle total de 'nossas ações', afinal, 'temos' influências externas que contribuem para o deslocamento de nossas vontades, desvirtuando-as para outros caminhos que, às vezes, nem pensávamos trilhar.

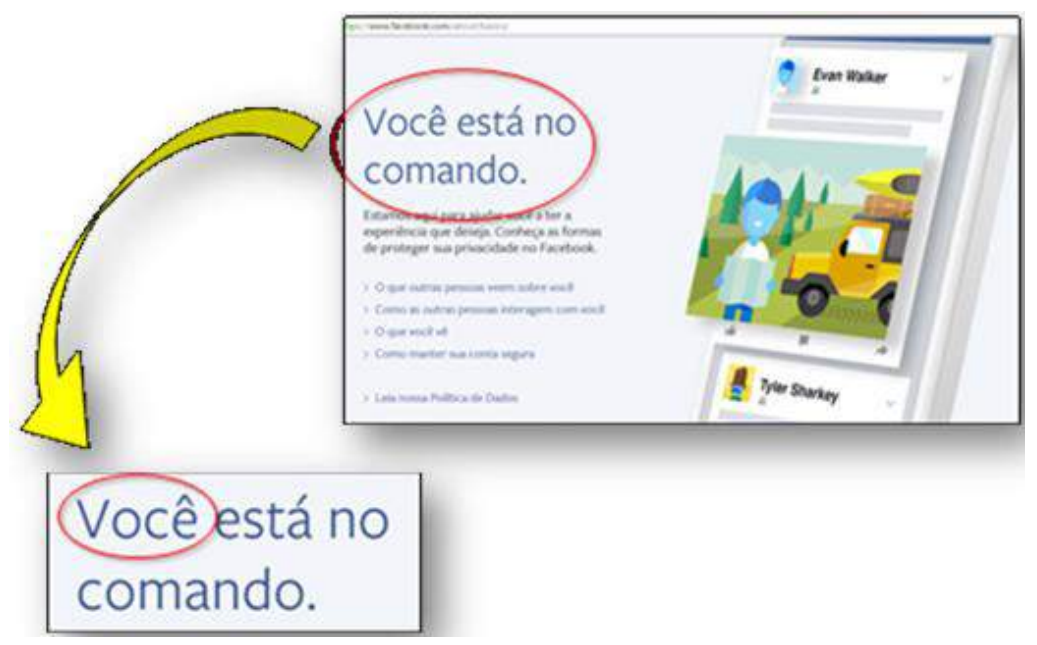

Figura 4. Termos de uso do Facebook. 'Você está no comando'. Fonte: Página pessoal do Facebook (2015)

A discursividade presente nos enunciados é formulada no interdiscurso - ou seja, segundo Piovezani e Sargentini (2011), no conjunto de formulações que dão sentido ao dito, associando outros ditos, independente de quem o disse, e quando o disse; nas formulações imediatas, ditas naquele momento, mas que são formuladas a partir de memórias discursivas, filiando-se às formações ideológicas.

Assim, como pode-se perceber no recorte, o enunciado 'você está no comando' se instaura na perspectiva do dizível (interdiscurso), bifurcando-se em dois eixos - o da memória (constituição) e o da atualidade (formulação) (ORLANDI, 2015a) -, resgatando já ditos enunciados sobre a temática do comando, ou melhor dizendo, das relações de poder inscritas no ato de comandar.

Levando-se em consideração que o Facebook é um software 'gratuito' (para o usuário, mas não para os anunciantes), ele se utiliza deste fator como ponto de atratividade de usuários; porém, a contrapartida do sedimento da utilização se formula, justamente, na utilização desta rede em fazer uso de dados dos usuários como informações para fins publicitários - mesmo que implícitos, através do envio do banco de dados dos usuários para marcas que adotam uma publicidade agressiva. A partir desta análise, sustenta-se a ideia de 'ilusão de estar no comando', fazendo-nos perceber que existem limites entre nossas vontades e as execuções que realmente funcionam na conceituada rede social. Segundo Ferreira (2015), as tecnologias não se tratam da extensão dos sujeitos, pois além de prolongarem suas competências, esses as transformam para produzirem efeitos sobre os sujeitos - como no caso, 'a ilusão de estar no comando'.

Uma vez vivendo intensamente em uma 'vida instantânea' (BAUMAN, 2000), o ser humano desenvolve, cada vez menos, a virtude da paciência, do esperar, do 
desenvolvimento que em muitos processos instauram-se de forma lenta e dificultosa. Vive-se em uma era em que o imediatismo toma conta de nosso tempo, colocando-nos em condições de produção favoráveis para tal agilidade, confundida com a rapidez em comandar e, em tempo recorde, obter resultados deste comando, desta forma ignorando os processos em longo prazo.

'Estar no comando' 'coloca-nos' em uma posição-sujeito de poder, em que as escolhas são verdades incontestáveis. Na conjuntura do funcionamento do Facebook, esta 'impressão de comando' é de extrema importância, uma vez que o usuário está adepto, a partir do pensamento e através de poucos cliques, a satisfazer suas vontades e obedecer às suas delegações, fielmente.

Os baús dos povos antigos representam a utilização do cadeado como trancamento de preciosidades das famílias - objetos de heranças, fotografias, mapas, joias, etc. Tais objetos, escolhidos pelos seus donos, eram fruto de valores materiais e de valores emocionais; valores afetivos para com os guardados (PÊCHEUX, 1988).

No recorte mostrado pela Figura 5, nos deparamos com uma variação do ícone, cujo símbolo principal ainda é o 'cadeado', porém um novo signo passa a fazer parte do objeto: 'um coração dentro do cadeado'. Junto a este ícone, o enunciado 'preferência de privacidade', descreve a ideia central de utilização deste comando.

A associação da palavra 'preferência' ao 'coração', evidencia o sentido de privacidade como critério pessoal e afetivo sobre a preservação da intimidade - lugar (Facebook) onde a escolha do que será postado, será uma opção que legitimará a individualidade da mesma, pois não foi utilizada a palavra preferência em suas várias formas e possibilidades, mas sim, de 'preferência' enquanto unicidade da preferência maioral, da preservação íntima.

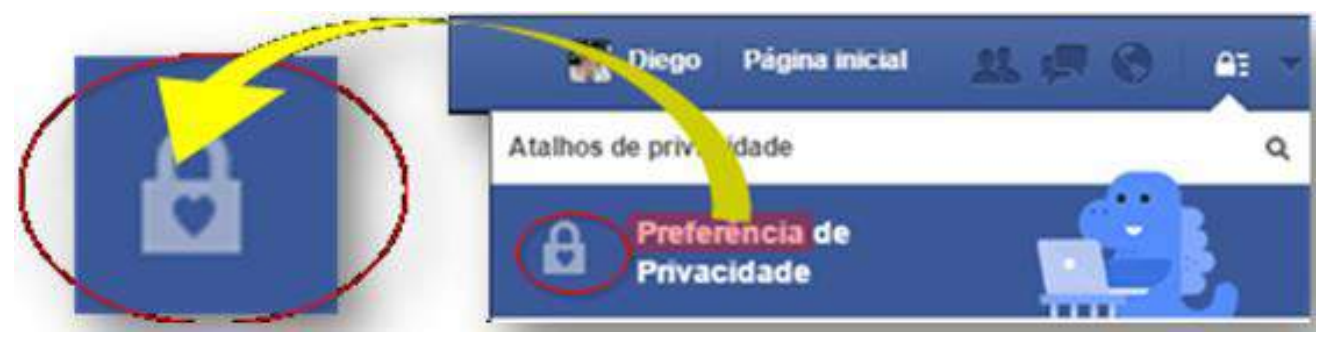

Figura 5. Preferências de privacidade do Facebook. Fonte: Página pessoal do Facebook (2015).

Prefere-se algo em detrimento de outra coisa. A escolha lexical (da palavra) aqui, mais do que falar sobre o modo como se pode configurar o Facebook, apela à questão que se caracteriza pela criação de um efeito de sentido de que 'há liberdade de escolha', por isso há mais de uma opção. Ao mesmo tempo em que está presente um efeito de sentido de 'prisão', há esse (efeito de sentido) de 'liberdade'.

O coração funciona na memória discursiva apelando às questões relacionadas aos 'sentimentos'. Neste caso, associado ao signo de um 'coração lúdico', desenhado, afastando-se da memória da fisiologia humana - ou seja, a imagem do coração como ele é fisicamente, acionando a 'memória sentimental' e emotiva que a imagem resgata. A 
mesma, não possui o mesmo efeito de sentido, neste caso, sem a ligação com o cadeado, haja vista que se analisa o sentido de público e privado em tal ícone de rede social tão massificada no Brasil.

Dias (2012), em sua obra que trata da discursividade da rede, registra que a hipertextualidade e os efeitos da tecnologia sobre o discurso fazem com que a memória seja evidenciada e não apagada. Já, segundo Fontana (2005, p. 97), “o arquivo, à diferença da memória discursiva, estrutura-se pelo não-esquecimento, pela presença, pelo acúmulo pelo efeito de completude".

Deste modo, enquanto a memória discursiva faz parte de um processo histórico, resultante de uma disputa de interpretações para acontecimentos do presente ou do passado, a memória metálica surge como o contraponto à memória histórica. Cada uma das memórias acarreta diferenças na relação entre constituição, formulação e circulação de sentidos, ao mesmo tempo em que cada uma também afeta, de modos diferentes, a função-autor e o efeito-leitor (DIAS, 2012).

A Análise de Discurso afirma que não existem verdades concretas sobre um dito, muito menos sentidos literais; o que se busca fazer nesta disciplina é compreender o funcionamento do discurso, perante determinadas condições de produção (MALDIDIER, 2003).

Assim, ainda relacionando à palavra 'preferência' ao ícone analisado, percebe a discursividade através do deslocamento deste enunciado, às demais noções da importância de 'poder escolher' e de 'poder de comando' baseados na preferência. Logo, chega-se às funções parafrásticas e, no lugar de preferência poderia ser dito: 'autonomia de escolha' e 'predileção a algo e escolha intimista'.

Partindo do pressuposto de que tais paráfrases representam o sentido do mesmo, ao mesmo passo em que tencionam com o diferente (com aquilo que pode ser dito de maneiras diferentes), pode-se observar de que modo os efeitos de sentido também podem sofrer deslizes (ORLANDI, 2015a). O próprio ato de 'preferir' coloca-se em uma situação de 'escolha'; pois, quando se escolhe algo, automaticamente, se abre mão do que não foi escolhido. Desta forma, ao utilizar a palavra 'preferência', o impacto da 'escolha' é menos explícito, fazendo a ponte entre o ato emocional de (poder) escolher.

\section{Considerações finais}

Muito além de uma relação social, em que proporcionar interações entre pessoas seja seu principal expoente, a privacidade no Facebook vai além da responsabilidade social e, de forma não transparente, como a linguagem, busca ser assegurada por aspectos legais da responsabilidade civil. A rede social, como mecanismo da evolução tecnológica, atrela-se ao Direito, andando em consonância com a legislação regulatória, dadas as circunstâncias de existência de relações humanas em seu âmbito.

Contudo, compreende-se, neste artigo, que os sentidos de privacidade no Facebook (público e privado) vêm sofrendo deslocamentos, considerados pelas 
ferramentas na evolução tecnológica, em que a memória metálica (ORLANDI, 2015b) se firma, constituindo diferentes sujeitos de discurso.

Compreende-se, também, que o sentido de público filia-se ao capitalismo e à promoção individual, interagindo com as esferas públicas ou de politização. Filia-se, ainda, à privatização das vertentes públicas, na acirrada busca da sensação de se tornar celebridade, que toma lugar da subjetividade interior e cede espaço para o espetacular 'show do eu' (SIBILIA, 2008).

Conclui-se que a disposição física dos atalhos (ícones) na rede social pode colocar em funcionamento o sentido de 'facilidade', silenciando o sentido de interferências externas ao fazer escolhas - incide aí a ilusão de estar no comando.

\section{Referências bibliográficas}

ARENDT, H. A condição humana. 10ª ed. Rio de Janeiro: Forense, 2007.

BAUMAN, Z. Modernidade Líquida. Rio de Janeiro: Zahar, 2000.

BRASIL. Casa Civil. Lei n. 12.965, de 13 de abril de 2014. Estabelece princípios, garantias, direitos e deveres para o uso da internet no Brasil. Disponível em http://www.planalto.gov.br/ccivil_03/_ato2011-2014/2014/lei/112965.htm. Acesso em 7 mai. 2016.

CHIARETTI, Paula. Discurso, subjetividade e novas tecnologias: você, sem fronteiras. RUA, Labeurb, Unicamp, Campinas (SP), jun. 2016. Disponível em http://www.labeurb.unicamp.br/rua20anos/web/index.php?r=paginasartigo\%2Fviewpag ina\&numeroPagina=1\&artigo_id=52. Acesso em: 26 jul. 2016.

CORBIN, Alain. O segredo do indivíduo. Em: PERROT, M. (Org.). História da vida privada. São Paulo: Companhia das Letras, 1990.

DIAS, Cristiane. Sujeito, sociedade e tecnologia: a discursividade da rede (de sentidos). São Paulo: Hucitec, 2012.

DINIZ, M.H. Curso de direito civil brasileiro. Responsabilidade Civil. 29a . ed. São Paulo: Saraiva, 2015.

FERREIRA, A.C.F. O papel e o poder fundador da linguagem na reflexão sobre conhecimento e tecnologia. Entremeios [Revista de Estudos do Discurso], Pouso Alegre, v. 11, 75-98, jul./dez. 2015. Disponível em http://www.entremeios.inf.br/published/300.pdf. Acesso em 14 jan. 2017.

ZOPPI-FONTANA, M.G. Arquivo jurídico e exterioridade. A construção do corpus discursivo e sua descrição/interpretação. Em: GUIMARÃES, E.; PAULA, M.R. de. (Orgs.). Sentido e memória. Campinas: Pontes, 2005. 
HENGER, G. da S.; BEHENCK, R.L. O discurso da Análise do Discurso: quando língua e história se encontram. Anais do Celsul, 2008. Disponível em http://www.celsul.org.br/Encontros/08/lingua_e_historia.pdf. Acesso em 14 jan. 2017.

KIRKPATRICK, David. O efeito Facebook. Rio de Rio de Janeiro: Intríseca, 2011.

LEMOS, R.; DI FELICE, M. A vida em rede. Campinas: Papirus, 2014.

LEONARDI, M.. Responsabilidade civil dos provedores de serviço de internet. São Paulo: Juarez de Oliveira, 2005.

MALDIDIER, D. A inquietação do Discurso. Trad. Bras. Campinas: Pontes, 2003.

NUNES, S.R. Práticas de leitura no infográfico eletrônico: trajetos, tropeços e movimentos. Em. DIAS, C. (Org.). Formas de mobilidade no espaço e-urbano: sentido e materialidade digital. [Série e-urbano, v. 2], 2013. Disponível em http://www.labeurb.unicamp.br/livroEurbano. Acesso em 30 jul. 2016.

ORLANDI, Eni Puccinelli. Análise de Discurso: princípios \& procedimentos. $12^{\mathrm{a}}$. ed. Campinas: Pontes, 2015a.

Maio de 1968: os silêncios da memória. Em: ACHARD, P. et. al. Papel da Memória. 4a . ed. Campinas: Pontes Editores, $2015 \mathrm{~b}$.

A contrapelo: incursão teórica na tecnologia: discurso eletrônico, escola, cidade. Rua, n. 16, v. 2, Campinas, Labeurb/Unicamp, 2010. Disponível em http://www.labeurb.unicamp.br/rua/pages/pdf/16-2/1-16-2.pdf. Acesso em 14 jan. 2017.

O que é linguística. $2^{\mathrm{a}}$. ed. São Paulo: Brasiliense, 2009.

Interpretação: autoria, leitura e efeitos do trabalho simbólico. $5^{\text {a }}$. ed. Campinas: Pontes Editores, 2007.

PAYER, M.O. Linguagem e Sociedade Contemporânea - sujeito, mídia e mercado. Rua, Campinas, v. 11, n. 1, 9-25, 2005. Disponível em http://periodicos.sbu.unicamp.br/ojs/index.php/rua/article/view/8640774/8311. Acesso em 10 jun. 2016.

PÊCHEUX, M. O discurso: estrutura ou acontecimento. $4^{\text {a }}$. ed. Campinas, SP: Pontes Editores, 2006.

Semântica e Discurso: uma crítica à afirmação do óbvio. Campinas: Ed. da Unicamp, 1988.

PIOVEZANI, C; SARGENTINI, V. (Orgs.). Legados de Michel Pêcheux: inéditos em análise do discurso. São Paulo: Contexto, 2011.

SENNETT, R. O declínio do homem público. As tiranias da intimidade. São Paulo: Companhia das Letras, 1993. 
SIBILIA, P. O show do eu: a intimidade como espetáculo. Rio de Janeiro: Nova Fronteira, 2008.

TATEOKI, V.A.; PEREIRA, L.M. Responsabilidade civil do provedor de aplicações Facebook, de usuários e terceiros. JusBrasil, jan. 2016. Disponível em http://victortateoki.jusbrasil.com.br/artigos/257798565/responsabilidade-civil-doprovedor-de-aplicacoes-Facebook. Acesso em 7 mai. 2016.

Artigo recebido em: outubro de 2016.

Aprovado e revisado em: dezembro de 2016.

Publicado em: abril de 2017.

\section{Para citar este texto:}

PEREIRA, Diego Henrique. Sentidos de privacidade no facebook: o cadeado como perspectiva de poder de comando e ilusão de estar no controle. Entremeios [Revista de Estudos do Discurso, on-line], Seção Estudos, Programa de Pós-Graduação em Ciências da Linguagem (PPGCL), Universidade do Vale do Sapucaí (UNIVÁS), Pouso Alegre (MG), vol. 14, p. 93-110, jan. - jun. 2017.

DOI: http://dx.doi.org/10.20337/ISSN2179-3514revistaENTREMEIOSvol14pagina93a110 